\title{
PRÁTICAS DE LEITURA NA BIBLIOTECA ESCOLAR: RELATO DE PESQUISA
}

\author{
Rosângela Félix de Santana \\ Aluna do Curso de Graduação em Biblioteconomia - UFPB \\ ufpbrosangela@gmail.com \\ Eliane Bezerra Paiva \\ Professora adjunta do Departamento de Ciência da Informação/CCSA/UFPB \\ Doutora em Linguística. \\ paivaeb@gmail.com
}

\section{Resumo}

\begin{abstract}
A biblioteca escolar pode desempenhar papel preponderante ajudando a promover competências em informação e colaborar para a formação de leitores críticos. Trata-se do relato de uma pesquisa, de cunho exploratório-descritivo, dentro de uma abordagem quantiqualitativa e que teve como objetivo analisar as práticas de leitura dos alunos do $9^{\circ}$ ano da Escola Municipal Violeta Formiga, localizada na cidade de João Pessoa. A pesquisa realizada demonstrou carências da biblioteca escolar: espaço físico insuficiente, falta de bibliotecário atuando, ausência de incentivos às práticas de leitura. A biblioteca escolar deve ser um espaço dinâmico de aprendizagem e incentivador das práticas de leitura.
\end{abstract}

Palavras-chave: Práticas de leitura. Biblioteca Escolar. Bibliotecário.

\section{INTRODUÇÃO}

O relatório elaborado pela Comissão Internacional pela Educação, para o Século XXI, solicitado pela UNESCO, aponta como princípios norteadores para uma educação pluridimensional e democrática, quatro pilares da educação: aprender a conhecer, a fazer, a viver juntos e a ser. Esses princípios tornam-se fundamentais na sociedade atual onde a informação desfruta valor imensurável. Nesse contexto, a biblioteca escolar pode desempenhar papel preponderante ajudando a promover competências em informação e colaborar para a formação de leitores críticos. Entretanto, vários estudos como os de Carvalho e Pontes (2003), Tavares, Silva e Valério (2013), Lima e Silva (2015) Oliveira e Campello (2016) demonstram que as bibliotecas escolares brasileiras padecem de diversos problemas: espaços físicos inadequados; são tratadas como um depósitos de livros; carecem de bibliotecários; dentre outros.
O presente texto é o relato de uma pesquisa que teve como objetivo analisar as práticas de leitura dos alunos do $9^{\circ}$ ano da Escola Municipal Violeta Formiga, localizada num bairro periférico da cidade de João Pessoa, Paraíba. Trata-se de uma pesquisa de cunho exploratório-descritivo, dentro de uma abordagem quanti-qualitativa. A pesquisa incluiu duas fases: uma pesquisa bibliográfica sobre as temáticas práticas de leitura, biblioteca escolar e usuários da informação, e uma pesquisa de campo, que se constituiu na aplicação de um questionário, composto por questões abertas e fechadas, que foi aplicado a 29 alunos do $9^{\circ}$ ano da referida escola, durante o mês de maio de 2016. Com a pesquisa, buscou-se uma reflexão sobre as condições de funcionamento da biblioteca e as práticas leitoras dos alunos, defendendo-se que a biblioteca escolar deve se constituir um organismo vivo e atuante para a formação de leitores críticos.

2 BIBLIOTECA ESCOLAR E PRÁTICAS DE LEITURA 


\section{Anais do Encontro Paraibano de Biblioteca Escolar}

O entendimento do que é biblioteca escolar surgiu com Aristóteles e muitos a consideravam a mais importante antes da biblioteca de Alexandria. Ele fundou um Liceu em Atenas e estabeleceu pela primeira vez uma íntima ligação entre a escola e esse novo espaço intelectual que é a biblioteca.

Segundo Ribeiro (1994) a Biblioteca Escolar tem um caráter de co-responsável no processo ensino-aprendizagem, surgindo a necessidade de considerar a qualidade do acervo e, consequentemente, dispensar maior atenção com o conteúdo do material disponível aos seus usuários.

Para Stavis, Koch e Drabik (2001, p. 36):

[...] a biblioteca escolar deve incentivar e disseminar o gosto pela leitura junto à criança, por meio do acervo organizado e integrado aos interesses da instituição, bem como da estrutura e funcionamento. A biblioteca escolar em cumprimento a sua função educativa motiva a busca pelo conhecimento, desenvolve no aluno o gosto e o hábito pela leitura e atitude de busca da informação.

Mas, na realidade, não é bem assim que funciona. Embora a Lei 12.244 (BRASIL, 2010), instituída em 24 de maio de 2010, que dispõe sobre a universalização das bibliotecas nas instituições de ensino do país, por falta de investimento do poder público, as escolas públicas não mantém, em sua maioria, uma biblioteca e muito menos uma biblioteca bem estruturada fisicamente e com um acervo adequado às necessidades; e quando possui uma biblioteca não há um profissional bibliotecário nem projetos de incentivo à leitura, deixando assim de cumprir sua função educativa junto a essas crianças.

A biblioteca tem como uma de suas funções básicas a relação social com a comunidade e faz parte do mundo dinâmico de promoção da leitura; função essa que busca a promoção de práticas informacionais e culturais visando facilitar o acesso e o uso da informação para atrair os usuários/leitores para compartilhar novas formas de aprender.

De acordo com Borba (1999, p. 35) as funções principais da biblioteca são: "prover os meios para atender aos interesses da leitura dos usuários", promovendo o gosto e a prática da leitura e formando cidadãos/leitores para que se tornem críticos perante a sociedade. Nas unidades de informação, mais especificamente nas bibliotecas, é no decorrer da formação dos usuários que o contato com a leitura deve se tornar mais evidente, auxiliando o papel dos pais e educadores de onde se inicia a difícil tarefa de despertar o gosto pela leitura. Pois, segundo Bortolom et al. (1998, p. 118) "no Brasil a escola talvez seja o único lugar onde a grande maioria das pessoas tem contato com o livro."

Pois como sabemos, a formação do leitor se dá inicialmente dentro da família, pois, é importante que se estimule o interesse da criança em aprender. Na escola esta ação de ler será aperfeiçoada no desempenho de sua função social, pois é um espaço adequado por contar com profissionais que auxiliam no processo da aprendizagem.

A biblioteca por estar inserida na escola, estabelece o papel de dinamizar e ativar a percepção crítica do aluno por meio de ações conjuntas com pais, educadores e bibliotecários.

Os bibliotecários auxiliam nesse processo que, além de executarem os processos técnicos da Biblioteconomia, incumbem-se do papel de mediador da informação.

Os especialistas em informação destacaram algumas competências do profissional da informação que, segundo Faria et al. (2005, p.27), configura-se em "conhecimento interdisciplinar e especializado, contextualização, conceituação, domínio de ferramentas e de tecnologia de informação, entre outros." Estes devem orientar, capacitar e elaborar planos de incentivo à leitura por meio de um melhor uso dos recursos de informação que cada unidade de informação disponibilizar, deve gerir a informação, ser capaz de se comunicar, ter um bom relacionamento interpessoal e conhecer mais de um idioma.

Hillesheim e Fachin (2003, p.38) salientam que:

[...] cabe ao bibliotecário e somente a ele a função de priorizar as tarefas do processamento técnico e as de atendimento à comunidade escolar para buscar a satisfação dos usuários; cabe a ele demonstrar a importância de seu trabalho como educador, 


\section{Anais do Encontro Paraibano de Biblioteca Escolar}

como incentivador da leitura, representando o real significado da biblioteca escolar.

Por isso, a presença desse profissional é de extrema importância em qualquer unidade de informação e mais ainda em uma biblioteca escolar onde as crianças iniciam esse processo de aprendizagem e esses profissionais atuarão como educadores e incentivadores da leitura.

As práticas de leitura são de extrema importância, principalmente nos dias atuais, pois nossa sociedade é globalizada e competitiva. Mas, é importante não apenas ler, como também compreender de forma cognitiva o que se está lendo. $\mathrm{O}$ ato de ler para Brandão e Micheletti (2002, p. 9), portanto;

É um processo abrangente e complexo; é um processo de compreensão, de intelecção de mundo que envolve uma característica essencial e singular ao homem: a sua capacidade simbólica e de interação com o outro pela mediação de palavras. $\mathrm{O}$ ato de ler não pode se caracterizar como uma atividade passiva.

Faz-se necessário que os indivíduos, antes de ler as palavras escritas, façam uma leitura de seu mundo (FREIRE, 1989), suas experiências e vivências, ensinamentos diários e o que vivenciam ao longo da vida.

Como diz Iser "os procedimentos mais diversos da interpretação, a leitura dos textos é uma pressuposição indispensável, ou seja, um ato que sempre antecede os atos interpretativos e seus resultados" (1996, p.49). Com isso, entende-se que antes de mais nada, é preciso fazer a leitura, para então fazer a interpretação do que está escrito.

A leitura é importante para que se tenha conhecimento da realidade e compreenda a realidade do outro, possibilitando interação. Pois "é ela quem permite ao leitor/a a liberdade de imaginar situações, traçar relações, preencher lacunas e desvelar sentidos ocultos, podendo enfim, mediar, compreender, interpretar." (HATOUM, 2005, p.27).

Segundo Silva (1985, p. 22) "O processo de leitura apresenta-se como uma atividade que possibilita a participação do homem na vida em sociedade, em termos de compreensão do presente e passado e em termos de possibilidades de transformação sociocultural futura."

Para tanto, Silva (1985, p. 62) sugere que $\mathrm{o}$ ato de ler seja visto como "um instrumento de conscientização e libertação, necessário a emancipação do homem na busca incessante de sua plenitude". Fornece subsídios para a mudança de mentalidade, comportamento social e abre as portas para a avaliação e crítica dos fatores que norteiam a sociedade, a fim de elaborar novos conceitos, formular conhecimento e contribuir para o crescimento da vida social.

Assim, esses/as cidadãos/ãs poderão modificar o espaço a sua volta, lutando por melhorias para si e para a sociedade na qual estão inseridos/as.

\section{SOBRE A ESCOLA E A BIBLIOTECA}

A Escola Municipal Violeta Formiga localiza-se na cidade de João Pessoa, no bairro de Mandacaru, à rua Alfredo José de Ataíde, s/n. Foi fundada no ano de 2008, durante a gestão do então governador do estado Ricardo Coutinho, prefeito naquela ocasião.

A escola recebeu este nome em homenagem a uma poetisa que foi assassinada. É uma escola de ensino fundamental, com alunos do $1^{\circ}$ ao $4^{\circ}$ ano no turno da tarde e do $5^{\circ}$ ao $9^{\circ}$ ano no turno da manhã, com a Educação de Jovens e Adultos (EJA) à noite.

A Biblioteca da escola resume-se a uma sala localizada nas proximidades do pátio da escola. A entrada para a biblioteca se dá por uma porta sinalizada com o nome "Biblioteca". Existem duas funcionárias da escola que atendem na biblioteca, uma no período da manhã e a outra à tarde.

O acervo, composto de livros didáticos e paradidáticos, não está catalogado e não há sinalização para sua recuperação. As estantes são em granito, tanto as paredes quanto as prateleiras, contribuindo para que o acervo fique protegido de insetos bibliófagos, como traças e cupins. A biblioteca dispõe de duas mesas e onze cadeiras, onde os alunos disputam o espaço para ler e/ou estudar. Ao entrar na biblioteca, à direita, localiza-se um 
espaço, denominado "Cantinho da leitura", onde se encontram os livros paradidáticos, que é sinalizado, ao fundo, por um painel, feito manualmente, com letra visível. Embora disponha de um espaço pequeno, a biblioteca é bastante frequentada pelos alunos da escola.

\section{PRÁTICAS DE LEITURA NA BIBLIOTECA DA ESCOLA MUNICIPAL VIOLETA FORMIGA}

A maior parte dos alunos pesquisados (79,3\%) disse frequentar a biblioteca, são, portanto, usuários reais. Ou seja, usuários reais ou efetivos "são aqueles usuários conhecidos que realmente utilizam os serviços da unidade de informação". (FARIA, 2010). Apenas 20,7\% não a frequentam. Seria importante existirem projetos de incentivo à leitura para atrair esses jovens à biblioteca, como gincanas culturais, hora do conto, teatro, concursos de poesia, já que a maioria disse gostar de ler poemas, enfim, algo que pudesse ser feito para despertar o interesse deles na biblioteca.

A maioria dos alunos relatou frequentar a biblioteca uma vez por semana $(37,9 \%)$, outros informaram que a frequentavam muito raramente $(27,6 \%)$, enquanto informaram frequentar todos os dias $(24,1 \%)$, disseram ir duas ou três vezes por mês $(6,9 \%)$ e disseram ir uma vez por mês $(3,4 \%)$.

Como se viu, ainda é muito baixa a frequência dos alunos na biblioteca, porque isso acontece? Faz necessária a presença de um profissional bibliotecário para criar projetos que estimulem esses jovens a gostarem de frequentar a biblioteca.

A questão referente à frequência à biblioteca incluía um espaço para que os alunos justificassem a sua resposta. Dentre as justificativas apresentadas pelos alunos porque não frequentam a biblioteca, as respostas foram diversificadas. Alguns se reportaram à falta de incentivo:

\footnotetext{
"As vezes por falta de incentivo ou influências” (A13)

"Por quê a professora não leva. É (sic) eu não tenho muita vontade de ler..." (A23)
}

Um aluno alegou que, às vezes, não frequenta a biblioteca por questões relativas ao espaço físico da biblioteca:

"Não frequento muito porque as vezes a biblioteca fica lotada e não da para entra (sic) para ler livros porque as vezes tem aluno fazendo prova la (sic) e as vezes não da para ler." (A16)

Outros alunos foram espontâneos e apontaram preguiça e o fato de não gostar de ler:

\section{"Por falta de vontade e preguiça” (A22) \\ "Porque não gosto muito” (A29)}

Mais uma vez percebe-se que a questão da falta de incentivo à leitura está presente nas respostas dos alunos pesquisados. $\mathrm{O}$ que se pode fazer para modificar isso? Por isso, vale enfatizar quão se faz importante que a escola promova projetos de incentivo, que possam atrair esses jovens para o ambiente da biblioteca e para que desperte um maior interesse pelas práticas de leitura. Também seria importante ampliar o espaço da biblioteca, pois os alunos a consideram pequena, isso ficaria a cargo do órgão responsável, para que o espaço fosse maior e mais confortável para acolher esses usuários.

No que concerne ao serviço de empréstimo, a maior parte dos alunos informou fazer uso do serviço de empréstimo $(55,2 \%)$, e outros que não o utilizam $(44,8 \%)$.

Quando os dados foram coletados, no mês de maio de 2015, como a biblioteca não dispõe de computadores, ficava uma funcionária na biblioteca e quando os alunos necessitavam, pegavam os livros e ela anotava manualmente o empréstimo.

Em relação à quantidade de livros requisitados, a maioria dos alunos respondeu não lembrar $(34,4 \%)$, outros alegaram ter pego de 1 a 3 livros (31,0\%), enquanto outros disseram não ter pego nenhum $(13,8 \%)$ e os que disseram que requisitaram de 3 a 6 livros; 6 a 12 e 12 a 20, incidiram (6,9\%), cada.

Esse resultado da pesquisa, referente à faixa etária pesquisada, de 13 a 16 anos, condiz com a pesquisa Retratos da Leitura no Brasil (INSTITUTO PRO-LIVRO, 2011), realizada 
em 2007, pois o número de livros lidos por ano por pessoas de 11 a 13 anos foram de 8,5 livros por habitante/ano e em 2011 houve uma redução, foi para 6,9 livros por habitante/ano. Já em relação às idades de 14 a 17 anos, foram de 6,6 livros por habitante/ano em 2007, onde também teve uma redução para 5,9 livros por habitante/ano.

Quais seriam, então, as causas dessa redução? Acredita-se que quando a escola e a biblioteca não desempenham, de forma eficaz seu papel de incentivadores da leitura, aplicando projetos para atrair esses jovens ao ambiente da biblioteca e a tomarem gosto pela leitura, isso pode ser um dos motivos. Outro motivo para essa redução poderia ser por causa dos novos suportes que surgiram na sociedade, tais como os computadores, pois a maioria dos jovens preferem ler pelo computador, por esses oferecerem uma busca vasta de assuntos em pouco tempo.

Quanto às atividades desenvolvidas com mais frequência na biblioteca, a maioria respondeu estudar/ fazer trabalhos de casa $(41,9 \%)$, em seguida ler/ consultar livros $(22,6 \%)$. Os que disseram fazer outras atividades $(16,1 \%)$, dentre essas atividades citaram tirar fotos e jogar, alguns disseram ouvir música $(12,9 \%)$, ler e/ou consultar jornais e revistas $(3,2 \%)$ e estudar para testes teve $(3,2 \%)$.

$\mathrm{O}$ item ler/consultar livros teve uma porcentagem pequena, mostrando que os jovens usam mais o espaço da biblioteca para estudar e fazer os trabalhos de casa, que não deixa de ser interessante, mas também para desenvolver outras atividades não muito importantes, como tirar fotos e jogar. Seria muito bom que usassem o espaço para ler mais, tomando gosto pela leitura, tornando-se leitores assíduos e bem informados, trazendo melhores benefícios no futuro.

\section{CONSIDERAÇÕES FINAIS}

A biblioteca escolar é um instrumento inicial para a formação leitora dos indivíduos, principalmente quando crianças. Muitas vezes a prática de leitura inicia-se na biblioteca da escola, pois é lá que terão um contato maior com os livros e a leitura.
Mas, por se tratar de biblioteca de uma escola pública, infelizmente, deixa a desejar, pois os investimentos nas unidades de informação são bastante escassos.

A biblioteca da escola pesquisada não possui um profissional bibliotecário. A profissão de bibliotecário, sua função e importância, ainda não foram reconhecidas como deveriam, apesar de existir a Lei 12.244 (BRASIL, 2010), instituída em 24 de maio de 2010, que dispõe sobre a universalização das bibliotecas nas instituições de ensino do país, ainda não perceberam quão dinamizador e importante seria ou será manter um profissional bibliotecário nas bibliotecas, desenvolvendo ações junto com os professores para atrair crianças, adolescentes e jovens ao ambiente da biblioteca e despertar neles a prática de leitura.

Com a pesquisa, conclui-se que se faz de suma importância que haja investimentos por parte do poder público, para, a princípio ampliar o espaço da biblioteca, tornando-o capaz de suprir a demanda em um ambiente mais confortável e atrativo.

Por se tratar de uma instituição pública, os alunos estudados possivelmente têm alguns obstáculos para a obtenção das informações que desejam, a exemplo: o obstáculo financeiro, pois a biblioteca onde foi realizada a pesquisa não possui computadores para que os alunos/usuários possam pesquisar as informações que necessitam, isso foi um dos itens que mencionaram no questionário, eles(as) gostariam que a biblioteca possuísse computadores, isso despertaria o interesse deles(as) para frequentarem mais o espaço.

Há também a barreira de eficiência na referida biblioteca, pois não há um mediador da informação, que seria o bibliotecário que poderia auxiliar os usuários na busca de tais informações. Esse seria mais um passo, um dos mais importantes para a biblioteca, pois ele, por se constituir um incentivador da leitura poderia estimular desde cedo a prática de ler nessas crianças e jovens, junto com os professores, desenvolvendo também seu papel de educador. Ambos poderiam organizar ações de incentivo à leitura e implantar projetos que pudessem despertar nos alunos(as) essa prática. Na realidade se sabe que não é tarefa fácil, pois não depende 
apenas deles, precisam esperar que as autoridades competentes invistam recursos e boa vontade em tal iniciativa.

A pesquisa realizada demonstrou carências da biblioteca escolar: espaço físico insuficiente, falta de bibliotecário atuando, ausência de incentivos às práticas de leitura.

A biblioteca escolar deve ser um espaço dinâmico de aprendizagem e incentivador das práticas de leitura. $\mathrm{O}$ bibliotecário é o profissional habilitado para atuar na biblioteca escolar e torná-la um centro de informação e de dinamização da leitura.

\section{REFERÊNCIAS}

BORBA, Maria do Socorro de Azevedo. Adolescência e leitura: a construção da escola e da biblioteca escolar. Natal: UFRN, 1999.

BORTOLOM, M.A. et al. Levantamento das características culturais no hábito de leitura da comunidade acadêmica do Curso de Biblioteconomia da Universidade Federal de Santa Catarina. Revista ACB, Florianópolis, v. 3, n. 3, p. 113-123, 1998.

BRANDÃO, Helena H. Nagamine; MICHELETTI, Guaraciaba. Teoria e prática da leitura. In: Coletânea de textos didáticos. Componente curricular Leitura e elaboração de textos. Curso de Pedagogia em Serviço. Campina Grande: UEPB, 2002.

BRASIL. Lei 12244, de 24 de maio de 2010. Dispõe sobre a universalização das bibliotecas nas instituições de ensino do país. Disponível em: $<$

Http://www.planalto.gov.br/ccivil_03/_ato20 07-2010/2010/lei/112244.htm> Acesso em: 10 jun. 2016.

CARVAlHO, A.M. S.; PONTES, R.B. Por espaços democráticos de aprendizagem. Transinformação, Campinas, v.15, n. 3, p.339-350, set./dez. 2003.

FARIA, Cleide Vieira de. Identificação das necessidades informacionais e comportamento de busca dos usuários da
Biblioteca Central da UFMG: ênfase nos alunos de graduação do Instituto de Ciências Exatas e Instituto de Ciências Biológicas. 2010. 66f. Monografia (Especialização em Gestão Estratégica da Informação) Universidade Federal de Minas Gerais, Programa de Pós-graduação do Núcleo de Informação Tecnológica e Gerencial -NITEG, Belo Horizonte.

FARIA, Sueli et al. Competências do profissional da informação: uma reflexão a partir da Classificação Brasileira de Ocupações. Ciência da Informação, Brasília, D.F., v. 34, n. 2, p. 26-33, maio/ago. 2005.

FREIRE, Paulo. A importância do ato de ler: em três artigos que se completam. 23 ed, São Paulo: Cortez, 1989.

HATOUM, M. O leitor, cúmplice secreto. EntreLivros, São Paulo, v.1, n.8, p.26-27, dez. 2005.

HILLESHEIM, A. I. A; FACHIN, G. R. B. Biblioteca escolar e a leitura. Revista ABC, Florianópolis, v. 8, n. 1, p. 35-45, 2003.

INSTITUTO PRÓ-LIVRO. Retratos da leitura no Brasil. 3. ed. São Paulo, [2012].

ISER, Wolfgang. $\mathbf{O}$ ato da leitura: uma teoria do efeito estético. São Paulo: 34,1996, v.1.

LIMA, L.M.A.; SILVA, R.J. Histórico das bibliotecas escolares no Estado do Paraná. Biblioteca Escolar em Revista, Ribeirão Preto, v.3, n. 2, p.53-71, 2015.

OLIVEIRA, I. R.; CAMPELLO, B. S. Estado da arte sobre pesquisa escolar no Brasil. TransInformação, Campinas, v.28, n. 2, p. 181-194, maio/ago. 2016.

RIBEIRO, M. S. P. Desenvolvimento de coleção na Biblioteca Escolar: uma contribuição à formação crítica sócio-cultural do educando. Transinformação, v. 6, n. 1/2/3, p. 60-73, jan./dez. 1994. 
SILVA, E.T. Leitura $\boldsymbol{\&} \quad$ realidade /revista_PEC/biblioteca_escolar_ao_alcance.p brasileira. 2.ed. Porto Alegre: Mercado df >. Acesso em: 18 maio 2015.

Aberto, 1985.

TAVARES, A. L. L.; SILVA, T. J.;

STAVIS, J. C.; KOCH, M. M. G.; DRABIK, VALÉRIO, E. D. Biblioteca Escolar:

V. R. Biblioteca escolar ao alcance das mãos. Revista PEC, Curitiba, v.1, n.1, p.35-38, jul.2000-jul.2001. Disponível instrumento para a formação de leitores críticos. Revista ACB: Biblioteconomia em em:<http://www.bomjesus.br/publicacoes/pdf Santa Catarina, Florianópolis, v. 18, n. 1, p.639- 657, jan./ jun. 2013. 